\title{
TEORIA SOCIAL E MEIO AMBIENTE: REFLEXÕES A PARTIR DAS MOTIVAÇÕES DE CONSTITUIÇÃO DE UM BOSQUE URBANO
}

\section{SOCIAL THEORY AND ENVIRONMENT: REFLECTIONS FROM THE SETTING UP OF MOTIVATIONS OF AN URBAN FOREST}

\author{
FELIPE BUENo AMARAL \\ Doutorando em Sociologia na Universidade Federal do Paraná (UFPR). É graduado em Gestão Ambiental pela \\ Universidade do Oeste de Santa Catarina (UNOESC) e Mestre em Sociologia pela UFPR \\ amaralfelipeb@gmail.com
}

José LUiz Fernandes Cerveira Filho Possui Graduação em Ciências Sociais pela Universidade Estadual de Londrina (UEL), Mestrado em Sociologia Política pela Universidade Federal de Santa Catarina (UFSC) e Doutorado em Ciências Sociais pela Universidade Federal de São Carlos (UFSCar). Foi Coordenador do Programas de Pós-Graduação em Meio-Ambiente e Desenvolvimento da Universidade Federal do Paraná (PPGMADE/UFPR), onde atualmente é professor e pesquisador. Também atua no Departamento de Ciências Sociais (DECISO) e no Programa de Pós-Graduação em Sociologia (PPGSocio). Tem experiência em trabalhar a interdisciplinaridade entre as áreas de Energia, Ambiente e Sociedade, em contexto rural e urbano, através, principalmente, das contribuições advindas das Sociologias Rural e Ambiental e das Políticas Públicas Ambientais, com ênfase nos seguintes temas: ruralidades e ambiente, relação energiaambiente-sociedade, conflitos socioambientais rurais, agroenergia, geração distribuída, biocombustíveis, recursos hídricos, saneamento e mobilidade pirajucerveira@hotmail.com

\section{RESUMO}

Este artigo se insere nas reflexões socioambientais contemporâneas que partem das contribuições da teoria da ação e da racionalidade desde Max Weber. Neste estudo nos debruçamos no processo de constituição de um bosque urbano dentro de uma região de casas de alto padrão, de um pequeno município da região metropolitana de Curitiba, PR, com interesse de perseguir e compreender as motivações desta constituição. Com esse intento, a pesquisa foi realizada num período de dois meses, onde frequentamos 0 bosque e entrevistamos a comunidade do entorno e também os organismos da prefeitura do município, relacionados a construção e manutenção de parques, praças e bosques. Foi possível perceber que dentre as múltiplas motivações da constituição do bosque estudado, a principal delas resultou de um conflito social entre dois grupos, entre indivíduos que utilizavam o bosque de modo distinto. Através disso constatou-se que as noções de natureza e meio ambiente, estão diminuídas ante outras noções como segurança e legislação, e sobretudo, que o meio ambiente não está descolado das ações dos indivíduos.

Palavras-chave: Indivíduo; Sociedade; Meio Ambiente; Bosque urbano; Teoria da ação.

\begin{abstract}
This article is inserted in contemporary social and environmental considerations departing the contributions of the action theory and rationality from Max Weber. In this study we worked through in an urban forest formation process within a region of highend homes, a small municipality in the metropolitan region of Curitiba, PR, with interest to pursue and understand the motivations of this constitution. With this intent, the survey was conducted over a period of two months where we attend the woods and interviewed the surrounding community as well as the bodies of the municipal council, related to construction and maintenance of parks, squares and woods. It was revealed that among the many root causes of the constitution of the studied forest, the main one was the result of a social conflict between two groups of individuals who used the differently grove. Thereby it was found that the notions of nature and the environment, are decreased at other notions such as security and legislation, and above all, that the environment is not taken off the actions of individuals.
\end{abstract}

Keywords: Individual; Society; Environment; Urban forest; Theory of action. 


\section{SUMÁRIO}

INTRODUÇAO; 1 APONTAMENTOS ACERCA DA TEORIA DA AÇÃO SOCIAL: INDIVÍDUO, SOCIEDADE E AMBIENTE; 2 RELAÇÕES ENTRE SOCIEDADE E AMBIENTE: UMA DESCRIÇÃO A PARTIR DAS APREENSÕES DO TRABALHO DE CAMPO; 2.1 Grupo 1 e as relações com o ambiente; 2.2 Relação do grupo 1 e o bosque: aparece um novo elemento; 2.2.1 Descrição dos usos do bosque pelo grupo 2: outras razões; 2.3 Apreensões do grupo 1 em relação ao grupo 2; CONCLUSÃO; REFERÊNCIAS.

\section{INTRODUÇÃO}

As reflexões que mobilizamos desde as relações entre ambiente e sociedade suscitam inúmeras indagações. Em linhas gerais, elas partem da controvertida distinção natureza e cultura, onde nos questionamos sobre seus limites, afinal, onde está a natureza? Essa é uma questão relativamente fácil de resolver se estivermos em uma região bucólica do mundo rural, por exemplo, onde todos os sentidos se encontram com a natureza incontrolável, enigmática e assustadora, donde justamente emerge a cultura na intenção de controlá-la. Mas se torna uma questão delicada se refletida desde o centro de uma grande cidade, ou em qualquer dos andares de um edifício. Mas aí então é tudo cultura? Afastamos todo o incompreensível da natureza e criamos formas alheias de diálogo com o mundo? Onde se encontram natureza e cultura?

Parece-nos mais fácil a partir da leitura da sociologia e mesmo dos manuais de gestão ambiental localizar as diferentes culturas, então, nos resta dentro da imaginação sociológica, localizarmos o lugar da natureza ou, das naturezas; por isso, tornamos a nos perguntar: onde está a natureza? Em nosso estudo, centramos os esforços, sobretudo, na movimentação de determinados sujeitos dentro de um espaço social delimitado, com propósito de constituir um bosque urbano, um representante da natureza cercado de representantes da cultura. A investigação seguiu nesse sentido, ou seja, de descobrir as motivações dessa constituição, a partir da teoria da ação.

Para perseguir este objetivo central visitamos o bosque durante dois meses de pesquisa, ora observando seus usos e conversando com frequentadores, ora entrevistando membros da prefeitura. No entanto, nosso foco central eram os moradores que residem no entorno do bosque, nas casas que o cercam, os moradores que fizeram parte do processo que ocorreu desde meados de 2012, ano em que o bosque recebeu bancos e pista de caminhada, um lago, postes de iluminação, uma cerca que o rodeava em sua totalidade e vigia 24 horas por dia. Remontamos a partir do campo as motivações desta construção, sua história, a parte que cabia ao poder 
público, afinal o bosque é municipal, e a parte da sociedade que o circunda, para desvelar suas demandas em relação à constituição.

Inegável que a noção de crise ambiental, e nela a noção de risco, se assoma sobre nossas cabeças de tal modo que os hábitos mais simples são a cada dia questionados e transformados, num apelo dos porta-vozes da natureza, numa tradução das ameaças e danos a ela causados. Essa tradução, essa representação que permeia as vivências, vem em forma de alerta ao mundo, como se dissessem que a cultura que um dia fora ameaçada pela natureza, está agora, como que em vingança ou revanche, ameaçando de morte a natureza.

Essa ameaça, que carrega em si inúmeras controvérsias, produz aquilo que Ulrich Beck (1995) chamou de sociedade de risco, onde o humano agora não escapa de perceber o mundo reflexivamente, como um espelho, como se cada ação projetasse seus reflexos inescapavelmente, de tal forma que um copo de café sugere não só pensar na escassez da água ou a utilização de agrotóxicos, mas também sobre o trabalho escravo e a movimentação da bolsa de valores. É a partir desta noção de risco que nossa análise das ações se desenvolve.

Nas linhas que se seguem optamos por dividir o texto em duas partes principais; na primeira visitamos a teria da ação, de Max Weber a Anthony Giddens e, na segunda, descrevemos o que apreendemos no campo, através das observações e dos relatos dos indivíduos pesquisados. Ressaltamos que o texto se presta a uma reflexão muito ampla, em uma tentativa de acrescentar o ambiente (ou a natureza) à teoria da ação. Reconhecemos os limites de nosso movimento teórico, mas insistimos que, desde esse estudo defendemos que o ambiente é um eixo fundamental da análise das ações acrescentadas ao esquema indivíduo x sociedade.

\section{APONTAMENTOS ACERCA DA TEORIA DA AÇÃO SOCIAL: INDIVÍDUO, SOCIEDADE E AMBIENTE}

Este trabalho pretende estabelecer um diálogo entre a teoria da ação e a epistemologia ambiental. Nesse sentido apostamos em uma exposição da teoria da ação nesta primeira seção, que vai de Max Weber a Anthony Giddens. Devemos assinalar que o Weber mobilizado aqui, dado seu alcance epistemológico, será o autor heterodoxo e que se ocupou das questões mais conceituais de sua ciência. Além das teorias weberianas, no intuito de avançar o alcance analítico, e transcender a oposição sujeito/sociedade, traremos as discussões de Anthony Giddens (2009) dentro da sua teoria da estruturação. Para uma crítica a noção de contexto deste 

MOTIVAÇÕES DE CONSTITUIÇÃ̃O DE UM BOSQUE URBANO

último, acrescentamos a noção de malha formulada por Tim Ingold (2011), a fim de contemplar o ambiente no esquema analítico da ação.

Portanto, apresentaremos nossas reflexões a partir destes autores dentro da grande teoria da ação social, sumariamente, na busca de tensionar as ações e motivações de criação do bosque estudado. É ainda válido ressaltar que a teoria analítica aqui desenhada é uma proposta, e que, dentro da teoria da ação, poderemos acessar outros autores que muito em razão dos espaço que temos aqui, não são apresentados no texto.

Feitas as contas, já dissemos que Max Weber é um autor de grande alcance e que sua teoria tem múltiplas interpretações; nos restringimos aqui aos conceitos estabelecidos pelo autor, a fim de não comprometer ou distorcer a análise. Optamos, para adentrar na teoria weberiana, em desenvolver seu conceito de sociologia, que ele define como uma "ciência que pretende compreender interpretativamente a ação social e assim explicá-la causalmente em seu curso e em seus efeitos" (1991, p.3). Para Weber,

A ação social (incluindo tanto a omissão como aquiescência) pode ser orientada para as ações passadas, presentes ou futura de outros. Assim, pode ser causada por sentimentos de vingança de males do passado, defesa contra perigos do presente ou contra ataques futuros. Os 'outros' podem ser indivíduos conhecidos ou desconhecidos, ou podem constituir uma quantidade indefinida. Por exemplo, 'dinheiro' é um meio de troca que o indivíduo aceita em pagamento, porque sua ação se orienta na expectativa de que numerosos, mas desconhecidos e indeterminados 'outros' o aceitarão por sua vez, em algum tempo no futuro, como um meio de troca (WEBER, 2010, p. 37. Grifos do autor).

Para seus estudos orientados principalmente na área econômica, jurídica e religiosa, a maior parte deles sob o olhar sociológico, o autor estabeleceu tipos de ação racional: ação racional com relação a fins; ação racional com relação a valores; ação racional com relação estritamente afetivo e ação tradicional ${ }^{1}$. Entretanto, devemos ressaltar a observação que Weber faz em relação aos tipos de ação. Segundo o autor,

só muito raramente a ação, e particularmente a ação social, orienta-se exclusivamente de uma ou de outra destas maneiras. E, naturalmente, esses modos de orientação de modo algum representam uma classificação completa de todos os tipos de orientação possíveis, senão tipos conceitualmente puros, criados por fins sociológicos, dos quais a ação real se aproxima mais ou menos ou

\footnotetext{
${ }^{1}$ Em nossas investigações a respeito das racionalidades weberianas, localizamos outros vários tipos de ação racional tributadas a Weber mas, que não localizamos na obra do próprio autor. Podemos afirmar por hora que Weber tinha uma concepção pluralista e relativista sobre racionalidade.
} 

MOTIVAÇÕES DE CONSTITUIÇÃO DE UM BOSQUE URBANO

dos quais - ainda mais frequentemente - ela se compõe. Somente os resultados podem provar sua utilidade para nossos fins (WEBER, 1991, p. 16).

Importante perceber que Weber não determina que esses sejam os únicos tipos de ação social, nem que uma ação seja manifesta por um único tipo puro, nem tampouco restringe a construção de outros modelos para que se ajustem aos propósitos de cada pesquisa ou pesquisador. Ao estabelecer isso, o autor abre possibilidades para que se possa utilizar adequadamente sua metodologia. Em Weber (2001), a sociologia constrói os tipos ideais a fim de descobrir as regras gerais do acontecer. É válido ressaltar que os tipos são formulados, inicialmente, através de uma exageração consciente das características essenciais da ação que interessa ao pesquisador e, posteriormente, da orientação sintética dessas características em um conceito unificado e desenvolvido com muito rigor, documentando as regularidades das ações significativas de modo preciso. Conforme ensina Kalberg (2010) os tipos só poderão ser construídos a partir do contato empírico, com intuito de formar um constructo homogêneo e preciso, para por fim atingir uma explicação compreensiva válida.

Da obra de Anthony Giddens (2009), nos baseamos nas categorias analítico-metodológicas do autor, da mesma forma como fizemos com Weber; dessa forma, nos concentramos na obra A constituição da sociedade (2009), e nos restringiremos aos conceitos de sua teoria da estruturação; trata-se assim de uma opção nossa para esse artigo.

Primeiramente, devemos assinalar que Giddens avança o ponto de partida weberiano, em uma delimitação clara da não polarização sujeito/sociedade; para o autor, o dualismo, deve ser reconceituado para dualidade (GIDDENS, 2009). Significa isso que em sua concepção de estrutura (distinta do estruturalismo, que enfatiza a preeminência do todo social sobre partes individuais) a distinção sujeito/objeto, advinda do acento em questões epistemológicas (ou em suas disputas), gera um dualismo entre objetivismo e subjetivismo. Nesse sentido sua teoria da estruturação se centra em interesses ontológicos.

A noção de dualidade pode ser compreendida na passagem abaixo, onde não se enfatiza nem sujeito nem sociedade a partir da análise das ações:

Admito a exigência de que o sujeito seja descentrado e considero isso básico para a teoria da estruturação. Mas não aceito que isso implique na evaporação da subjetividade num universo vazio de sinais; pelo contrário, consideramos que as práticas sociais, ao penetrarem no espaço e no tempo, estão na raiz da constituição do sujeito e do objeto social (GIDDENS, 2009, p. XXIV). 

MOTIVAÇÕES DE CONSTITUIÇÃO DE UM BOSQUE URBANO

Uma vez exposto como a ação social deve ser compreendida dentro da teoria de Gidddens, avançamos para o conceito de ação do autor, onde este deve ser analisado a partir da dualidade da estrutura. Para ele, a ação é um processo, “um fluxo, em que a monitoração reflexiva que o indivíduo mantém é fundamental para o controle do corpo que os atores ordinariamente sustentam até o fim de suas vidas no dia-a-dia” (2009, p. 11). 0 autor vai além deste conceito quando desenvolve o conceito de agência; para ele agência se refere à capacidade do indivíduo de realizar uma determinada ação, que por sua vez está diretamente relacionada com a noção de poder, já que sob a noção de agência o ator poderia a qualquer momento mudar seu curso.

Tanto o conceito de ação como o de agência, se referem ainda aos conceitos de intenção, rotina e previsibilidade da ação, os quais não descreveremos dado o objetivo do texto, mas que, são indispensáveis na interpretação e o curso da ação. Basta enfatizar nas palavras do autor que a ação “depende da capacidade do indivíduo de 'criar uma diferença' em relação ao estado de coisas ou curso de eventos preexistente. Um agente deixa de o ser se perde a capacidade para 'criar uma diferença', isto é, para exercer alguma espécie de poder” (2009, p. 17. Grifos do autor).

Giddens ressalta ainda que a ação não deve ser concebida senão através da análise dualista entre indivíduo e sociedade, já que “[...] ao reproduzirem propriedades estruturais [...], os agentes também reproduzem as condições que tornam possível tal ação. A estrutura não tem existência independente do conhecimento que os agentes possuem a respeito do que fazem em sua atividade" (2009, p. 31). A análise da ação dentro da estrutura deve ser recursiva entre sujeito e sociedade; pensar o oposto disto, seria supor que atores determinados, estabelecem as propriedades estruturais de sistemas sociais.

A dualidade da estrutura é sempre a base principal das continuidades na reprodução social através do espaço-tempo. Por sua vez, pressupõe a monitoração reflexiva (e a integração) de agentes na durée da atividade social cotidiana. O fluxo da ação produz continuamente consequências que não estavam nas intenções dos atores, e estas também podem formar condições não reconhecidas de ação, nos moldes de um feedback. A história humana é criada por atividades intencionais, mas não constitui um projeto deliberado; ela se esquiva persistentemente dos esforços para colocá-la sob direção consciente. (GIDDENS, 2009, p. 31-32. Grifos do autor).

Talvez aqui deva-se ressaltar a imprevisibilidade da ação dentro da estrutura, e a reflexividade dos atores na realização das ações. Temos de remarcar que o autor aprofunda as 
motivações do agir individual, adentrando na rotina dos atores, vida cotidiana e reflexividade; Ao analista, portanto, cabe considerar a noção de contexto na interpretação das interações. Segundo o autor,

[...] o estudo do contexto, ou das contextualidades de interação, é inerente à investigação da reprodução social. O "contexto" envolve o seguinte: a) as fronteiras espaço-temporais (sendo usualmente marcos simbólicos ou físicos) em torno das faixas de interação; b) a co-presença de atores, possibilitando a visibilidade de uma diversidade de expressões faciais, gestos corporais, linguagem e outros veículos de comunicação; c) percepção consciente e uso desses fenômenos reflexivamente para influenciar ou controlar o fluxo de interação (GIDDENS, 2009, p. 332-333. Grifos do autor).

Não seria possível dar conta do glossário terminológico de Giddens para detalhar seu sistema analítico; este é um dos muitos alcances deste texto. Contudo, não podemos nos furtar de assinalar esta passagem que acabamos de extrair do autor sobre a noção de contexto. É justamente isto que permite que pensemos a ação em seu ambiente. Aos olhos do pesquisador, essas ações dos indivíduos devem estar sempre relacionadas, com o contexto em que ocorrem, na relação espaço-tempo. Para Giddens (2009, p. 337), analisar a coordenação espaço-temporal das atividades sociais "[...] significa estudar as características contextuais de locais onde os atores sociais se movimentam em seus percursos cotidianos e a regionalização de locais que se estendem através do tempo-espaço."

Entretanto em Giddens, esta noção diz respeito ao "encenamento da interação, os atores co-presentes e a comunicação entre eles” (2009, p. 440). Em nossa concepção esta definição aponta para extremos do fluxo da ação, onde o ambiente representa a cena, a moldura, o local onde a ação se desenrola. Isto é, ação aqui, ambiente ali - descolados. Sem dúvida que a inserção do ambiente como cena representa um avanço para a análise da ação. Mas gostaríamos de apontar para uma outra noção presente em Tim Ingold (2011), a noção de malha.

Para Ingold (2011) a noção de malha diz respeito diretamente a noção de vida, em uma conexão desta com o meio em que se desenvolve a ação num fluxo entre individuo, sociedade e seu meio ambiente. Cada um desses elementos no fluxo de constituição da vida, como um emaranhado de linhas entrelaçadas, mas possíveis de conexão com outros circuitos de vida. “Nessa perspectiva ecológica e relacional, já não faria sentido separar nem o organismo da pessoa, nem esse organismo-pessoa do entorno porque o que está em processo de desenvolvimento é a totalidade formada" (BONET, 2014, p. 334). Vale ressaltar que esse esquema não é uma entidade, ou seja, 
[...] não é um objeto independente fechado que está definido contra outros objetos com os quais pode então ser justaposto ou unido. É, sim, um pacote ou um tecido de linhas, fortemente unificadas, mas com alguns pontos em aberto, sem conexão, que se agrupam com outras linhas de outros agrupamentos (INGOLD, 2011, p. 91).

É claro que o envolvimento de teorias ao mesmo tempo contrapostas e similares demandaria um esforço teórico impossível de ser descrito neste espaço. A noção, entretanto, que temos de ressaltar aqui, é que a ação muito além de ser apenas dos indivíduos em um contexto, se dá essencialmente no ambiente e além, o ambiente é condição de possibilidade de interação e de desenvolvimento de vida. Dito de outra forma, o ambiente surge para nós como um agente participativo na ação.

\section{RELAÇÕES ENTRE SOCIEDADE E AMBIENTE: UMA DESCRIÇÃO A PARTIR DAS APREENSÕES DO CAMPO DE TRABALHO}

\subsection{Grupo 1 e as relações com o ambiente}

Ação e experiência se aplicam a todas as dimensões do viver.

A reflexão, própria do ser humano, apoia-se na linguagem que contém o mundo, pelo fazer de alguém em particular e em algum lugar.

Dimas Floriani, 2010.

Nesta seção do trabalho descrevemos o processo de constituição do bosque estudado. Operamos aqui com trechos das entrevistas realizadas nos organismos da prefeitura do município, onde está situado aquele equipamento urbano - departamento de planejamento urbano e departamento de parques, praças e bosques. Entrevistamos também a comunidade do entorno do bosque, que representamos no texto com grupo 1; por ocasião do surgimento de um novo grupo relacionado a constituição do bosque, o apresentamos também aqui como grupo 2 .

No departamento de planejamento urbano, e também no departamento de parques, praças e bosques, apreendemos que a noção de contexto histórico (crise ambiental) revela o que seria a motivação essencial da criação do bosque. Para a diretora do primeiro departamento, as alterações do município são causalmente determinadas pelas necessidades de proteção ambiental, ou seja, o desenvolvimento e criação de equipamentos públicos segue essa noção de 
contexto, que em última medida se relaciona com aquela noção de risco de Beck (1995). Desta forma, em relação a constituição do bosque em questão podemos perceber que sua fala vai nesse sentido:

\begin{abstract}
Algumas coisas por força do tempo, que aconteceria em algum tempo, às vezes são melhores administradas num período, às vezes melhor em outro, e até por força das necessidades que surgiu e que o administrador é obrigado a se adaptar a ela, seja conjuntura econômica, social ou ambiental ${ }^{2}$ (Diretora do Departamento de planejamento urbano).
\end{abstract}

Outra motivação que foi possível apreender para constituição do bosque, foi mobilizada através da legislação 67.6679, que determina que, quando uma grande parcela de terra é adquirida por uma empresa, nesse caso uma construtora, parte deste terreno deve ser destinada a prefeitura para execução de obras públicas de interesse da sociedade. Devemos remarcar que o bosque em questão existe há dois anos, em um loteamento que foi fracionado há quinze anos isso pode ser uma pista de outros condicionantes para criação do bosque, como veremos mais tarde.

0 bosque na verdade originalmente não foi concebido como um bosque exatamente, ele tomou esse nome e esse formato agora bem recentemente de dois anos pra cá, não mais do que isso, mas em 1998 quando houve a aprovação do loteamento, que era uma gleba que foi parcelada, a legislação requer que o loteador tenha áreas de uso institucional dentro do seu parcelamento. $\mathrm{Na}$ época da legislação que foi aprovado o loteamento era 35\% de área do loteamento, pela lei 67.6679 que é a lei federal do parcelamento, é obrigado a passar pro poder público, e isso incorpora o sistema viário necessário para ter acesso aos lotes, bem como lotes nos quais você possa implantar equipamentos pra essa população que você vai estar instalando ali de alguma forma, né (sic) (Diretora do departamento de planejamento urbano).

Podemos por hora perceber duas noções originárias da constituição do bosque; a) temos a crise ambiental que está em pleno debate desde meados do século passado (sociedade de risco), e também a b) legislação de parcelamento de lotes. Pode-se constatar aqui que estas duas noções se referem às razões técnicas. Em outras palavras, ambas fazem parte das necessidades instrumentais para se constituir um equipamento desta natureza, pois, se por um lado a lei de parcelamentos garante legalmente uma reserva de terra para a sociedade, por outro e aliada à primeira, a concepção de crise ambiental resultou que aquele espaço fosse transformado em um bosque, por estabelecer uma referência direta com natureza ou meio ambiente.

${ }^{2}$ As citações longas dos entrevistados serão assinaladas em itálico, para distinguir das citações longas dos autores. 
Neste sentido, foi possível captar algumas noções de meio ambiente, relacionadas com a noção de proteção e cuidado com os representantes da natureza; nos dois departamentos da prefeitura que tivemos acesso, essas impressões se revelam, inclusive relatando as características daquele ambiente. Entre a constituição inicial daquele ambiente (e aqui falamos somente da área do bosque) pode-se perceber também aqui uma relação com a técnica, que resulta na forma como ele está atualmente.

\begin{abstract}
Essa área era uma gleba e que tinham alguns condicionantes, como nascente e vegetação de bosque nativo que é essa parcela que está ali hoje no bosque. E foi feito um trabalho de engenharia; a nascente não era exatamente ali onde está hoje o lago constituído, ela era um pouquinho mais acima, foi feito um trabalho de rebaixamento desta nascente , se constituiu ali um lago e uma área verde aberta que incorporava o bosque, um gramado e um lago que foi ampliado, daí foi construído, ele não é original daquele lugar, ele foi construído ali, e foi passado para o poder público como uma área de uso institucional, uma área verde, que é uma área preservada ou conservada (Diretora do departamento de planejamento urbano).
\end{abstract}

Nesta fala se pode verificar como as razões técnicas foram fundamentais para a constituição do bosque. Da mesma forma, na citação abaixo, se constata o mesmo argumento onde se relacionam técnica e elementos da natureza presentes na construção daquele equipamento.

Então o bosque foi criado já com planejamento, já vinha sendo estudado já há tempo.Claro que falta ainda muitas coisas ali ainda, né, praticamente a mata ainda é nativa então a gente está plantando alguma coisa, e, aquele lago vai ser melhorado também, porque ele falta oxigênio, a gente tem uns peixes ali e de vez em quando a gente precisa fazer uma emergência por causa daqueles peixes, por causa de oxigênio. Aquele lago é mais alto que o nível da rua, e sai muita água, dá muita infiltração e vai embora água rápido, então a gente está estudando que vai ser melhorado o lago também (Diretor departamento de parques, praças e bosques).

Ainda na prefeitura captamos uma outra motivação, que posteriormente na fase de campo também foi apreendida através das entrevistas com os moradores do entorno do bosque. Há outro bosque na cidade, temporalmente anterior a este que analisamos, e que, devido seu sucesso, serviu como 'modelo' para este último - uma terceira motivação e que podemos relacionar também às razões técnicas. 0 sucesso a que nos referimos vem da frequentação que este primeiro bosque tem, propiciando que as pessoas do município não tenham que se deslocar para a capital em busca de lazer e um contato direto com a natureza. Segundo a diretora do 
departamento de planejamento urbano, explicando sobre o ambiente investigado, "a transformação dela em bosque com a estrutura que tem hoje, está muito mais relacionado ao sucesso do bosque aqui da área central, do que propriamente já de origem ter a ideia: aqui será um belo bosque".

Outra motivação que pode ser associada às razões técnicas, é o padrão das casas do entorno do bosque, que na apresentação deste texto identificamos como de alto padrão. Essa noção é importante para o que queremos demonstrar ao fim desta descrição. É importante na medida em que nos dá pistas, ainda que não definitivas, de uma das razões de criação do bosque. Temos de reforçar desde já: não partimos da premissa de que o bosque foi criado por uma motivação unilateral; de início, encontrar o bosque localizado nesta comunidade nos fez construir hipóteses das mais variadas, e estabelecer conexões de causalidade que posteriormente, afastados os preconceitos, percebemos não ser verdadeiras. Por hora, basta confirmar o que dissemos sobre o padrão das casas através das falas obtidas na prefeitura. Vamos então associar este padrão também às razões técnicas, mas essa associação é mais valorativa que as anteriores, ou seja, estamos veiculando a construção (técnica) do bosque às possíveis necessidades desta comunidade do entorno.

Segundo informações obtidas no departamento de planejamento urbano, no início da constituição do bosque, “[...] o loteamento foi todo infraestruturado, e as áreas foram vendidas a terceiros, os lotes estão praticamente todos construídos lá né, um loteamento com padrão relativamente bom para o município, principalmente em relação do que se tinha a época né".

Além de asseverar o perfil da região, ou seja, estamos falando de uma região de alto padrão, percebemos a primeira informação de utilização daquele ambiente; o bosque era subutilizado por aquela comunidade - aqui temos uma pista para a análise que faremos no próximo capítulo.

Para não deixarmos escapar nosso percurso analítico vamos retomar os pontos até aqui identificados. Vimos através dos relatos do poder público, na figura da diretora de planejamento urbano e do departamento de parques, praças e bosques, que uma das razões da criação do bosque foi a) o contexto atual de crise ambiental; outras duas razões apreendidas foram, b) a lei de parcelamento de lotes, e c) a referência ao sucesso do primeiro bosque do município. Uma quarta razão, mas a partir de uma instrumentalização valorativa nossa, é a d) criação do bosque em uma relação estética com o padrão das residências do entorno. Assim, a partir do contexto, aquela área reservada à prefeitura foi utilizada para a constituição do bosque, sinalizando que essa opção se relaciona diretamente com a necessidade de conservação da natureza. 
Se pudéssemos esquematizar a fim de sintetizar as apreensões até aqui obtidas, poderíamos ensaiar um quadro que estabelecesse a relação entre a prefeitura, o bosque e o grupo 1, nessa ordem. Nesse sentido, o bosque teria o papel central como fim para a solução dos problemas ambientais e legais de um lado, e estético ou paisagístico advindo do grupo 1, de outro, conforme descrito até aqui.

\title{
2.2 Relação do grupo 1 e o bosque: aparece um novo elemento
}

Ação e experiência se aplicam a todas as dimensões do viver. A reflexão, própria do ser humano, apoia-se na linguagem que contém o mundo, pelo fazer de alguém em particular e em algum lugar. Dimas Floriani, 2010.

Nesta seção do trabalho descrevemos o processo de constituição do bosque estudado. Operamos aqui com trechos das entrevistas realizadas nos organismos da prefeitura do município, onde está situado aquele equipamento urbano - departamento de planejamento urbano e departamento de parques, praças e bosques. Entrevistamos também a comunidade do entorno do bosque, que representamos no texto com grupo 1; por ocasião do surgimento de um novo grupo relacionado a constituição do bosque, o apresentamos também aqui como grupo 2 .

No departamento de planejamento urbano, e também no departamento de parques, praças e bosques, apreendemos que a noção de contexto histórico (crise ambiental) revela o que seria a motivação essencial da criação do bosque. Para a diretora do primeiro departamento, as alterações do município são causalmente determinadas pelas necessidades de proteção ambiental, ou seja, o desenvolvimento e criação de equipamentos públicos segue essa noção de contexto, que em última medida se relaciona com aquela noção de risco de Beck (1995). Desta forma, em relação a constituição do bosque em questão podemos perceber que sua fala vai nesse sentido:

\begin{abstract}
Algumas coisas por força do tempo, que aconteceria em algum tempo, às vezes são melhores administradas num período, às vezes melhor em outro, e até por força das necessidades que surgiu e que o administrador é obrigado a se adaptar a ela, seja conjuntura econômica, social ou ambiental ${ }^{3}$ (Diretora do Departamento de planejamento urbano).
\end{abstract}

Outra motivação que foi possível apreender para constituição do bosque, foi mobilizada através da legislação 67.6679, que determina que, quando uma grande parcela de terra é

\footnotetext{
${ }^{3}$ As citações longas dos entrevistados serão assinaladas em itálico, para distinguir das citações longas dos autores.
} 

MOTIVAÇÕES DE CONSTITUIÇÃO DE UM BOSQUE URBANO

adquirida por uma empresa, nesse caso uma construtora, parte deste terreno deve ser destinada a prefeitura para execução de obras públicas de interesse da sociedade. Devemos remarcar que o bosque em questão existe há dois anos, em um loteamento que foi fracionado há quinze anos isso pode ser uma pista de outros condicionantes para criação do bosque, como veremos mais tarde.

0 bosque na verdade originalmente não foi concebido como um bosque exatamente, ele tomou esse nome e esse formato agora bem recentemente de dois anos pra cá, não mais do que isso, mas em 1998 quando houve a aprovação do loteamento, que era uma gleba que foi parcelada, a legislação requer que o loteador tenha áreas de uso institucional dentro do seu parcelamento. $\mathrm{Na}$ época da legislação que foi aprovado o loteamento era $35 \%$ de área do loteamento, pela lei 67.6679 que é a lei federal do parcelamento, é obrigado a passar pro poder público, e isso incorpora o sistema viário necessário para ter acesso aos lotes, bem como lotes nos quais você possa implantar equipamentos pra essa população que você vai estar instalando ali de alguma forma, né (sic) (Diretora do departamento de planejamento urbano).

Podemos por hora perceber duas noções originárias da constituição do bosque; a) temos a crise ambiental que está em pleno debate desde meados do século passado (sociedade de risco), e também a b) legislação de parcelamento de lotes. Pode-se constatar aqui que estas duas noções se referem às razões técnicas. Em outras palavras, ambas fazem parte das necessidades instrumentais para se constituir um equipamento desta natureza, pois, se por um lado a lei de parcelamentos garante legalmente uma reserva de terra para a sociedade, por outro e aliada à primeira, a concepção de crise ambiental resultou que aquele espaço fosse transformado em um bosque, por estabelecer uma referência direta com natureza ou meio ambiente.

Neste sentido, foi possível captar algumas noções de meio ambiente, relacionadas com a noção de proteção e cuidado com os representantes da natureza; nos dois departamentos da prefeitura que tivemos acesso, essas impressões se revelam, inclusive relatando as características daquele ambiente. Entre a constituição inicial daquele ambiente (e aqui falamos somente da área do bosque) pode-se perceber também aqui uma relação com a técnica, que resulta na forma como ele está atualmente.

Essa área era uma gleba e que tinham alguns condicionantes, como nascente e vegetação de bosque nativo que é essa parcela que está ali hoje no bosque. E foi feito um trabalho de engenharia; a nascente não era exatamente ali onde está hoje o lago constituído, ela era um pouquinho mais acima, foi feito um trabalho de rebaixamento desta nascente , se constituiu ali um lago e uma área verde aberta que incorporava o bosque, um gramado e um lago que foi ampliado, daí foi construído, ele não é original daquele lugar, ele foi construído ali, e foi 
passado para o poder público como uma área de uso institucional, uma área verde, que é uma área preservada ou conservada (Diretora do departamento de planejamento urbano).

Nesta fala se pode verificar como as razões técnicas foram fundamentais para a constituição do bosque. Da mesma forma, na citação abaixo, se constata o mesmo argumento onde se relacionam técnica e elementos da natureza presentes na construção daquele equipamento.

Então o bosque foi criado já com planejamento, já vinha sendo estudado já há tempo.Claro que falta ainda muitas coisas ali ainda, né, praticamente a mata ainda é nativa então a gente está plantando alguma coisa, e, aquele lago vai ser melhorado também, porque ele falta oxigênio, a gente tem uns peixes ali e de vez em quando a gente precisa fazer uma emergência por causa daqueles peixes, por causa de oxigênio. Aquele lago é mais alto que o nível da rua, e sai muita água, dá muita infiltração e vai embora água rápido, então a gente está estudando que vai ser melhorado o lago também (Diretor departamento de parques, praças e bosques).

Ainda na prefeitura captamos uma outra motivação, que posteriormente na fase de campo também foi apreendida através das entrevistas com os moradores do entorno do bosque. Há outro bosque na cidade, temporalmente anterior a este que analisamos, e que, devido seu sucesso, serviu como 'modelo' para este último - uma terceira motivação e que podemos relacionar também às razões técnicas. 0 sucesso a que nos referimos vem da frequentação que este primeiro bosque tem, propiciando que as pessoas do município não tenham que se deslocar para a capital em busca de lazer e um contato direto com a natureza. Segundo a diretora do departamento de planejamento urbano, explicando sobre o ambiente investigado, "a transformação dela em bosque com a estrutura que tem hoje, está muito mais relacionado ao sucesso do bosque aqui da área central, do que propriamente já de origem ter a ideia: aqui será um belo bosque".

Outra motivação que pode ser associada às razões técnicas, é o padrão das casas do entorno do bosque, que na apresentação deste texto identificamos como de alto padrão. Essa noção é importante para o que queremos demonstrar ao fim desta descrição. É importante na medida em que nos dá pistas, ainda que não definitivas, de uma das razões de criação do bosque. Temos de reforçar desde já: não partimos da premissa de que o bosque foi criado por uma motivação unilateral; de início, encontrar o bosque localizado nesta comunidade nos fez construir hipóteses das mais variadas, e estabelecer conexões de causalidade que 
posteriormente, afastados os preconceitos, percebemos não ser verdadeiras. Por hora, basta confirmar o que dissemos sobre o padrão das casas através das falas obtidas na prefeitura. Vamos então associar este padrão também às razões técnicas, mas essa associação é mais valorativa que as anteriores, ou seja, estamos veiculando a construção (técnica) do bosque às possíveis necessidades desta comunidade do entorno.

Segundo informações obtidas no departamento de planejamento urbano, no início da constituição do bosque, “[...] o loteamento foi todo infraestruturado, e as áreas foram vendidas a terceiros, os lotes estão praticamente todos construídos lá né, um loteamento com padrão relativamente bom para o município, principalmente em relação do que se tinha a época né".

Além de asseverar o perfil da região, ou seja, estamos falando de uma região de alto padrão, percebemos a primeira informação de utilização daquele ambiente; o bosque era subutilizado por aquela comunidade - aqui temos uma pista para a análise que faremos no próximo capítulo.

Para não deixarmos escapar nosso percurso analítico vamos retomar os pontos até aqui identificados. Vimos através dos relatos do poder público, na figura da diretora de planejamento urbano e do departamento de parques, praças e bosques, que uma das razões da criação do bosque foi a) o contexto atual de crise ambiental; outras duas razões apreendidas foram, b) a lei de parcelamento de lotes, e c) a referência ao sucesso do primeiro bosque do município. Uma quarta razão, mas a partir de uma instrumentalização valorativa nossa, é a d) criação do bosque em uma relação estética com o padrão das residências do entorno. Assim, a partir do contexto, aquela área reservada à prefeitura foi utilizada para a constituição do bosque, sinalizando que essa opção se relaciona diretamente com a necessidade de conservação da natureza.

Se pudéssemos esquematizar a fim de sintetizar as apreensões até aqui obtidas, poderíamos ensaiar um quadro que estabelecesse a relação entre a prefeitura, o bosque e o grupo 1, nessa ordem. Nesse sentido, o bosque teria o papel central como fim para a solução dos problemas ambientais e legais de um lado, e estético ou paisagístico advindo do grupo 1, de outro, conforme descrito até aqui.

\subsubsection{Descrição dos usos do bosque pelo grupo 2: outras razões}

Quando estas famílias vieram pra cá, a primeira coisa que as crianças destas famílias fizeram, foi atravessar este belo campo (estendendo a palavra belo) que tinha aqui (agora região da nova relocação) e ir brincar no lago do bosque e isto foi muito complicado. Diretora do departamento de planejamento urbano. 
Com esta fala iniciamos nossa descrição das práticas do grupo 2 no bosque. Esta fala, em nossa interpretação, começa a lançar luz sobre essas práticas, e além disso, sobre as formas de apreensão do que se fazia naquele ambiente por parte dos moradores do entorno do bosque. Aqui pode-se perceber a forma como as crianças se relacionavam com o bosque, mas será demonstrado ao longo da descrição que as crianças brincando no lago constituem apenas um dos elementos de representação de uso do bosque por parte do grupo 2 .

Até aqui, o leitor percebe que chamamos de grupo 1 , os moradores que residem no entorno do bosque e que, denominamos grupo 2 , os moradores que residem nas proximidades do bosque, no conjunto habitacional próximo a ele. A primeira delas é mais fácil delimitar, ou seja, são somente os moradores do entorno do bosque. Quanto ao outro grupo, esta delimitação apresenta um pouco mais de dificuldades, ou seja, é à essas pessoas que na seção anterior o diretor do departamento de parques, praças e bosques se referiu ao mencionar as 634 famílias, e relacionar o bosque como uma área abandonada, e que a partir da instalação delas naquele ambiente, a polícia militar e a guarda municipal teriam mais problemas. Mas nosso grupo 2, é maior que isso. E são estas que aparecem na fala de abertura desta seção; onde antes era um "belo campo" - segundo a caracterização da diretora do departamento de planejamento urbano -, que as crianças atravessavam para chegar ao bosque, é agora o conjunto vizinho ao bosque. Isso quer dizer que existiam já outros conjuntos habitacionais próximos àquele das 634 casas. Então há uma noção temporal aqui que não contemplamos; assim, para tomarmos uma posição, quando falarmos em grupo 2, estamos falando de todos esses moradores oriundos dos conjuntos habitacionais.

O desenvolvimento de transformação do bosque portanto extrapola a implantação das casas populares. Podemos constatar essa informação também neste relato:

As crianças estavam acostumadas a brincar nas cavas dos rios, sem regras né, sem um comportamento muito civilizado como toda criança, então eles não tinham trajes adequados, comportamentos adequados e realmente é... a população que morava de frente pra aquela área que quando comprou achou linda e maravilhosa tomou um choque, e foi realmente a forma de uso totalmente inadequada. Primeiro que o lago não é pra banho. Imagina de um dia para o outro, e nós fizemos a relocação em outubro de 1998, já é uma época que começa a aquecer né, você imagina aquela criançada de beira de rio, né, criada solta, porque é o modo de vida dessas famílias, uma relação com o espaço totalmente diferente com aquele que está acostumado com a cerquinha né? $\mathrm{E}$ houveram assim ' $N$ ' queixas, reclamações, foram muitos os problemas, além do perigo porque não havia um controle do uso desse lago, então a criançada tirava 

MOTIVAÇÕES DE CONSTITUIÇÃO DE UM BOSQUE URBANO

a roupa e se lançavam pra dentro d'água e os vizinhos ficavam horrorizados (Diretora de planejamento urbano).

Podemos sintetizar várias passagens anteriores nesta última fala. Primeiro aqui a noção de temporalidade está presente, ou seja, o grupo 2, que foi retirada da beira de rio e instalada nas proximidades do bosque desde 1998, começa a acessá-lo, com comportamentos ditos inadequados e a partir disso o grupo 1, que escolheu aquele ambiente para residir, mobiliza 0 poder público para resolver aquilo que os horrorizavam e assustavam. Segundo a diretora do departamento de planejamento urbano, isso provocou uma ligeira tensão na prefeitura, já que um grupo determinado (grupo 2) estava invadindo o pretenso espaço de outro grupo determinado (grupo 1) e se comportando de modo, julgado por eles, inadequado.

\begin{abstract}
Mas infelizmente, desprovido de qualquer preconceito, o impacto que essa população causou naquele pequeno laguinho, foi quase o do pisoteio do gado na borda do lago. Porque foi tão intenso, tão imediato, e não estavam preparados pra isso, então foi assim, além do choque sociocultural que era esperado, e nós estamos passando isso da mesma maneira com esse novo loteamento, não está sendo diferente, porque aquela população que está ali, né, instalada, mora há quase 20 anos e acha que está numa condição diferente, se enxerga diferente, está tendo dificuldade em conviver, não com todos óbvio, mas com alguns desses novos moradores que não são assim pessoas que tem o hábito da cidadania, da convivência coletiva e da delimitação do espaço (Diretora do departamento de planejamento urbano).
\end{abstract}

O que se pode observar aqui é que na interpretação da prefeitura, o grupo 1 estabelece uma relação de distinção a partir de suas convicções, em direção às ações dos representantes do grupo 2 que frequentam o bosque. Pedimos que o leitor atente para a expressão 'choque cultural' utilizada pela diretora. Voltaremos a isso com maior atenção na próxima seção do trabalho onde daremos voz aos membros do grupo 1 por nós entrevistados. Por hora basta, assinalar que estes usos do grupo 2, demandou uma reação do grupo 1 , solicitando que o poder público interviesse no sentido de coibir aquelas ações. Segundo o diretor do departamento de parques, praças e bosques, “o maior fiscal de qualquer órgão público são os moradores. Então eles viam aquilo lá, ponto de droga na frente da casa deles, a molecada tomando banho numa água suja. Então reclamação total né." E conclui mencionando uma dada união do grupo 1 com a prefeitura: "aí se cria a comunidade junto com a prefeitura, junto com a secretaria, claro, já sabiam que o terreno era da prefeitura, e eu acho que foi um ponto muito positivo fazer aquele bosque ali" (diretor do departamento de parques, praças e bosques). 
Nesta seção foi possível perceber que esse novo elemento que se insere, o grupo 2, não está presente em nenhuma das razões apontadas no início das descrições, pelo menos não como uma forma de clara motivação de transformação do bosque - Talvez essa seja a principal motivação e arriscaríamos dizer aqui que nossa maior descoberta.

\subsection{Apreensões do grupo 1 em relação ao grupo 2}

A primeira entrevista que fizemos, depois de caminhar em frente as 32 casas que circundam o bosque, e tocar algumas campainhas, foi com uma mulher de meia idade e sua filha, aluna do primeiro ano do curso de fisioterapia. Apesar de termos sido convidados a entrar na casa, realizamos as entrevistas há poucos passos da porta da entrada e em pé. Na descrição identificaremos a mãe como Entrevistada 1 e a filha como Entrevistada 2. Temos de entender que, ainda que as duas habitem na mesma casa e tenham uma relação de parentesco, podem ter usos e percepções distintas do bosque.

Sobre a motivação do bosque, a Entrevistada 1 disse ter sido criado em relação ao primeiro bosque. Segundo ela, o que motivou a criação do equipamento "é que aqui na região não tinha área de lazer pra população, né. Então é isso que eu sei que o prefeito, o pessoal lá que achava que tinha que ter mais área de lazer, e daí foi feito aquele outro bosque, e depois esse" (Entrevistada 1). Novamente aparece aqui uma das razões técnicas que apontamos no início desta parte, ou seja, c) a referência ao sucesso do primeiro bosque do município. A Entrevistada 2 acrescenta que "nessa área aqui tava meio perdida e aproveitaram pra ter área de lazer pras crianças. E normalmente escolas trazem para fazer passeio. A guarda acompanha. Mais como área de lazer." Ressaltamos aqui que, em nossa compreensão, a utilização do bosque como área para passeio e lazer das crianças, não é motivadora da constituição do bosque, e sim, uma alternativa ante sua existência e disponibilidade.

Como já havíamos realizado as entrevistas nos departamentos da prefeitura, resolvemos questionar sobre outra motivação de criação questionando sobre a segurança do bosque antes da criação - esta questão surgiu após o aparecimento em nosso horizonte do grupo 2. Sobre esta noção de segurança, a Entrevistada 2 respondeu que

com certeza. Porque como era aberto essas casas aqui mais pro fundo, creio que quase todas elas foram assaltadas, como era aberto eles escondiam ali dentro do bosque e na hora que voltavam a noite aproveitavam para entrar junto. 
Aconteceu isso algumas vezes. E de usar drogas e essas coisas sempre tinha também (Entrevistada 2).

Aqui tornamos a perceber que a criação do bosque tinha relação com um tipo determinado de uso que se fazia dele. Apreendemos novamente aquela motivação descrita nas linhas acima, a partir das análises dos departamentos da prefeitura - e) os usos que o grupo 2 faz do bosque. Em relação com esses usos limites ou marginais, podemos avançar na descrição apontando mais duas falas - observamos ser impossível precisar se os assaltos tinham relação com o grupo 2. Na primeira, após ser questionada como estava o movimento no bosque a Entrevistada 1 disse que o movimento de crianças aumentou bastante, mas que não havia problemas para ela. Apesar disso, aponta saber de moradores que não compartilham deste pensamento. Para ela, “[...] vem pessoas de longe aqui fazer caminhada, trazer as crianças pra brincar. Mas tem moradores que aqui que não concordam com a chegada deles. Tem até residências pra vender por conta disso..." A Entrevistada 2 concorda dizendo que "eles acham que vai vir bandido, né. Mas, não é por que a casa deles é daquele jeito, que é doada né... que vai ter só bandido. Aqui quem me garante que não tem? Então, isso não quer dizer nada. É claro que deve ter, mas..." e a Entrevistada 1 conclui enfatizando:

Pessoas boas e más têm em qualquer lugar. Pessoas assim existem em qualquer lugar. Então têm pessoas que falam meio discriminando assim, eu acho que não é certo. Por que esse pessoal foi alocado pra cá porque moravam em área de risco, em beiras de rios, né, ai por um programa do governo eles trouxeram pra cá. Pra mim é indiferente eles ali. Não posso dizer que depois que eles vieram mudou. A única coisa que tem é que a gente ta acostumado com as pessoas que você vê, né. Ai esses dias comentei com ela (apontando para a Entrevista 2) que tem bastante gente diferente (Entrevistada 1).

Outra entrevistada, 3, nos recebeu na sala de sua casa, onde residem ela e o marido. 0 casal reside ali desde 2013, data de inauguração do bosque. Souberam da criação do bosque, antes da residência ficar pronta e quando se mudaram, ficaram sabendo da construção do conjunto habitacional. Ligado o gravador, realizamos a primeira questão do questionário, no intento de saber se ela frequentou ou frequenta o bosque. Segundo ela, antes da transformação, as idas ao bosque eram mais frequentes.

Olha como é interessante. Antes eu frequentei mais do que depois da reforma. Porque você vê, era um lugar assim, não era um lugar feio, mas não tinha nada de bom ali, apesar de a gente daí, como somos amigos ali da (nome de uma das 
vizinhas) ai a gente aos domingos ficava ali, naquele gramado, naquele morro, conversando, olhando algumas pessoas que vinham ali também. Mas frequento. Claro, vou lá dou ama olhada, uma caminhada. Mas pra você saber que bem curioso que eu me liguei agora que eu frequentava mais antes (Entrevistada 3).

Percebe-se novamente aqui uma forma de uso do bosque por parte do grupo 1. Apesar de não ter se envolvido na transformação do bosque, a Entrevistada 3 relata que o lugar era inseguro antes de ser concluída a construção. "Era muito inseguro. Os moleques vinham a noite. Tinha drogas. E daí as pessoas ficavam inseguras aqui, não sei, por preconceito, não sei... e era muito escuro antes da reforma aqui né." E conclui relembrando que "quando nós começamos a construir aqui, claro, minha casa né, lógico, a gente tava animado. Mas pensava um pouco na segurança. Ficava um pouco temeroso. Mas daí não né foi ótimo porque a gente sabia que ia melhorar tudo."

Sobre a implantação do conjunto habitacional a entrevistada nos traz uma perspectiva diferente:

Infelizmente eu também não gostei. Também acho que preconceito, com certeza. Mas isso foi no começo lá, quando eles começaram a construir tudo. Você fica assim já... mas depois eu fiquei sabendo que era pras pessoas que eles iam trazer pra cá as pessoas necessitadas e tal da beira do rio, ai eu fiquei mais tranquila. Ai passou aquilo. Num primeiro momento assim eu quase que fiquei revoltada, sabe. Porque a gente vem morar aqui com tanto sacrifício e eles... porque aqui eu considero um bom lugar pra morar, e daí pra falar sinceramente com você vem essas pessoas vem assim de graça, né, morar junto com a gente que... mas depois passou... foi passando, porque era preciso fazer isso. Enfim tranquilo, hoje tá tudo bem, algumas pessoas já estão ali (Entrevistada 3).

Pode-se perceber aqui que há uma noção clara de descontentamento que parece ir de encontro às outras motivações, ou seja, com essas famílias viriam insegurança, maus hábitos, drogas, etc. Mas ela pode ser extrapolada aqui. Como a Entrevistada 3 escolheu aquela região para morar, em conjunto com seu companheiro, ela achou injusto compartilhar a mesma região, a mesma sensação; em nossa compreensão isso se dá muito mais por um valor comercial da residência do que um privilégio de classe.

Essa impressão de privilégio pela região onde reside é compartilhada de um modo geral por todos os entrevistados. Percebemos isso quando entrevistamos as entrevistadas 4 e 5 . A entrevista foi realizada na calçada em frente a casa de uma delas - Entrevistada 5. Como essas duas moradoras residem há mais de 10 anos naquele local e viram todo o processo de transformação do loteamento, pôde-se apreender uma satisfação exacerbada para com o local; principalmente na contramão de tudo o que foi relatado até aqui como um problema, como 

MOTIVAÇÕES DE CONSTITUIÇÃO DE UM BOSQUE URBANO

segurança por exemplo. Essas categorias negativas apareceram de outro modo na fala das duas entrevistadas, e que não é possível representar no texto - assinalamos aqui uma das dificuldades em transmitir ao leitor a impressão exata do real através do texto escrito. A entrevistada 4, relata sobre sua percepção do bosque:

Antes eu não frequentava porque antes tinha maloqueiro ai dentro. Antes de fechar ai tinha drogado ai dentro e coisa e tinha. É claro, chamava a polícia e eles vinham. Mas sempre tinha uns drogados ai no meio. Vinham usar drogas ai dentro. Então as pessoas se cuidavam. Gerava um pouco de insegurança porque eles não incomodavam a gente aqui. Foi aumentando assim os moradores, e um ficava cuidando e quando viam já chamavam a polícia e eles vinham, então, eu não posso me queixar desse lugar aqui (Entrevistada 4).

Sobre a população do conjunto habitacional que foi implantado próximo ao bosque, e portanto, próximo da comunidade do entorno do bosque, obtivemos esta resposta da Entrevistada 4 "não posso dizer nada porque até agora não incomodaram. Eu tava com medo né, mas graças a deus. A gente não sabia quem que vinha pra cá. A gente só sabia que era turma da beirada do rio. Mas ali não é turma da beira do rio. Pode ser que lá embaixo. Aqui em cima não é.” Em expressarmos surpresa quanto a este último comentário, ela conclui dizendo que “[...] porque quem mora na beirada do rio não tem móveis que nem eles têm ali. Carro zerinho tudo (Risos). Você passe ali pra ver o que eles têm" (Entrevistada 4). A entrevistada 5 ratificava todas essas falas, e nos deu uma pista importante sobre a reação do grupo 1, sobre a ação do grupo 2 no bosque:

A Lú (apelido de uma moradora) sempre brigava por esse bosque né. Mas só que não deu tempo dela ver. Ela faleceu antes. Mas o pessoal antes sempre foi muito unido em questão disso daqui. A gente fazia mutirão pra varrer o bosque quando não era fechado aqui. Então a gente juntava todos os vizinhos aqui e um varria, porque era muito carro ali, e era muito escondido, então eles faziam de motel ali pra cima. Então a gente tinha que fazer sabe, o recolhimento das... (camisinhas) então a gente pegava sacos e sacos... ela dali, nós aqui... tudo se juntava um cortava a grama,... agora não né. Olhe que beleza [...] (Entrevistada 5).

Para além da questão do mutirão, em que se estabelece a noção talvez de pertencimento desta sociedade ao ambiente, há uma outra muito importante nessa direção: havia uma moradora que fazia abaixo assinados, coletava assinaturas dos moradores do grupo 1 e encaminhava para a prefeitura. A partir desta informação procuramos saber onde ela morava e se havia alguém da família que pudesse nos ajudar na obtenção desses documentos. 
Conseguimos falar com seu marido, apresentados pela Entrevistada 5, e este nos informou que teria de procurar mas que cederia os documentos, já que para ele não faziam diferença. Nos colocamos a disposição e retornamos algumas vezes mas não conseguimos obter esses documentos para anexar na pesquisa. Tentamos através da prefeitura, mas não obtivemos sucesso também lá.

As apreensões do Entrevistado 6 seguem o mesmo modelo dos demais entrevistados, incluindo a vinculação deste bosque com o primeiro bosque do município e, a sensação de insegurança gerada pelos indivíduos do grupo 2 naquele ambiente. “[...] Eu gostava mais antes. Não tinha essa 'muvuca'. Sábado e domingo fica cheio e tal né. Fica um monte de gente. Povão. Nada contra, mas na verdade eu não curto assim muito. Eu gosto bastante da natureza, mas eu vou longe assim." Além dos outros elementos que se repetem constantemente nas falas desses moradores, gostaríamos ainda um vez apresentar uma reação de completa aversão o grupo 2, apreendida anteriormente na prefeitura: a criação de um muro que garantisse a permanência da tranquilidade, civilidade e valorização do imóvel.

\begin{abstract}
Eu achei que ia me incomodar mais. Achei que eram pessoas favela e tal. Mas que eu notei desde que eles estão estabelecidos ali, tranquilo. Eu tenho um conhecido que vendeu aqui e começou a "povo vamos vender que os caras vão fazer um conjunto residencial ali atrás né" até eles queriam fechar na verdade. Aquela passagem, eles queriam fechar ali atrás. Mas não é meu estilo ficar fazendo essas associações ali, não tenho tempo (Entrevistado 6).
\end{abstract}

Aqui finalizamos a descrição da fala dos entrevistados e demonstramos ao longo destas seções, como o grupo 1 , se impõe através do poder público ao grupo 2 . Mais do que isso, chegamos ao final desta fase com o bosque deslocado de seu papel central.

\title{
CONCLUSÃO
}

Neste trabalho pudemos constatar as motivações de constituição de um bosque urbano específico, localizado em meio a uma comunidade de alto padrão de um pequeno município. Inicialmente, como hipótese, conjecturamos que a comunidade do entorno - grupo 1 - havia realizado a demanda à prefeitura, a fim de atender as satisfações estéticas e mesmo de valorização imobiliária. Foi possível perceber que das múltiplas motivações, as principais eram a) o contexto de crise ambiental, b) a legislação de parcelamento de lotes, c) sucesso de um 
outro bosque existente no município e, d) os usos que uma segunda comunidade - grupo 2 - fazia do bosque.

Esta última motivação se revelou em fato mais importante, já que nas entrevistas as noções de segurança e civilidade, se fizeram mais presentes. Segurança do grupo 1 em relação ao grupo 2, e padrões de comportamento do grupo 2 que o grupo 1 não aprovava. Essa descoberta nos revelou duas coisas: 1) que a questão de ambiental foi transformada essencialmente para social e, em consequência, 2) que o meio ambiente exerceu um papel ativo nas decisões dos sujeitos envolvidos, assim como ensinam Giddens (2009) e Ingold (2011), já que, o bosque foi deslocado do papel central que havíamos atribuído.

O deslocamento do papel central nas relações se demonstra através das noções do grupo 1, e suas menções a insegurança, valor, civilidade, etc., pois, podemos conjecturar que se não fosse um bosque com árvores, lago e trilhas, elementos que propiciaram a prática de comportamentos inadequados, e sim qualquer outro empreendimento como um condomínio por exemplo, os membros daquela sociedade, não sentiriam insegurança. Também é possível conjecturar que, mantida a constituição inicial do bosque, e as práticas fossem voltadas para execução de esportes ou dinâmicas artísticas, por exemplo, da mesma forma a sensação de insegurança não seria um problema essencial, e a preocupação possivelmente seria outra, ou seja, a centralidade está na ação, e não no bosque enquanto tal.

\section{REFERÊNCIAS}

BECK, Ulrich; GIDDENS, Anthony; LASH, Scott. Modernidade reflexiva: política, tradição e estética na ordem social moderna. São Paulo: Editora da Universidade Estadual Paulista, 1995.

BONET, Otavio. Interações e malhas para pensar os itinerários de cuidado: a propósito de Tim Ingold. Sociologia \& Antropologia. Rio de Janeiro, 2014.

FLEISCHMANN, Eugène (2001). De Weber à Nietzsche. European Journal of Sociology, 42, pp 243-292 doi:10.1017/S0003975600008249

FLORIANI, Dimas. Conhecimento, meio ambiente \& globalização. Curitiba: Juruá, 2010.

GIDDENS, Anthony. A constituição da sociedade. $3^{\circ}$. ed. São Paulo: Editora WMF Martins Fontes, 2009.

INGOLD, Tim. Being Alive: essays on movement, knowledge and description. Londres: Routledge, 2011. 
KALBERG, Stephen. Max Weber: uma introdução. Rio de Janeiro: Zahar, 2010.

WEBER, Max. A ética protestante e o espírito do capitalismo. São Paulo: Martin Claret, 2001

WEBER, Max. Conceitos Básicos de Sociologia. São Paulo: Centauro, 2010.

WEBER, Max. Economia e Sociedade: fundamentos da sociologia compreensiva. Brasília: UNB, 1991.

Recebido em: 27/10/2015 / Aprovado em: 12/12/2015 